\title{
Challenges in Detecting Clinically Relevant Heparin-Induced Thrombocytopenia Antibodies
}

\author{
Theodore E. Warkentin 1,2,3,4,5
}

${ }^{1}$ Department of Pathology and Molecular Medicine, Michael G. DeGroote School of Medicine, McMaster University, Hamilton, Ontario, Canada

2 Department of Medicine, Michael G. DeGroote School of Medicine, McMaster University, Hamilton, Ontario, Canada

${ }^{3}$ Transfusion Medicine, Hamilton Regional Laboratory Medicine

Program, Hamilton, Ontario, Canada

${ }^{4}$ Service of Clinical Hematology, Hamilton Health Sciences, Hamilton General Hospital, Hamilton, Ontario, Canada

${ }^{5}$ McMaster Centre for Transfusion Research, Hamilton, Ontario,

Canada

Hämostaseologie 2020;40:472-484.

\begin{abstract}
Address for correspondence Theodore E. Warkentin, MD, Hamilton Regional Laboratory Medicine Program, Hamilton General Hospital, Room 1-270B, 237 Barton St. E., Hamilton, Ontario L8L 2X2, Canada (e-mail: twarken@mcmaster.ca).
\end{abstract}

\section{Abstract}

Keywords

- chemiluminescent immunoassay

- heparin-induced thrombocytopenia

- latex immunoturbidimetric assay

- serotonin-release assay
Heparin-induced thrombocytopenia (HIT) is an antibody-mediated hypercoagulable state featuring high thrombosis risk and distinct pathogenesis involving immunoglobulin G-mediated platelet activation. The target of the immune response is a cationic "self" protein, platelet factor 4 (PF4), rendered antigenic by heparin. A key problem is that only a minority of anti-PF4/polyanion antibodies induced by heparin are pathogenic, i.e., capable of causing platelet activation and thereby clinical HIT. Since thrombocytopenia occurs frequently in hospitalized, heparin-treated patients, testing for "HIT antibodies" is common; thus, the problem of distinguishing between pathogenic and nonpathogenic antibodies is important. The central concept is that those antibodies that have platelet-activating properties demonstrable in vitro correlate well with pathogenicity, as shown by platelet activation tests such as the serotoninrelease assay (SRA) and heparin-induced platelet activation assay. However, in most circumstances, immunoassays are used for first-line testing, and so it is important for clinicians to appreciate which immunoassay result profiles-in the appropriate clinical context-predict the presence of platelet-activating antibodies (Bayesian analysis). Clinicians with access to rapid, on-demand HIT immunoassays (e.g., particle gel immunoassay, latex immunoturbidimetric assay, chemiluminescent immunoassay) can look beyond simple dichotomous result interpretation ("negative"|"positive") and incorporate semiquantitative interpretation, where, for example, a strong-positive immunoassay result (or even combination of two immunoassays) points to a greater probability of detecting platelet-activating antibodies, and hence supporting a diagnosis of HIT. Recent recognition of "SRA-negative HIT" has increased the importance of semiquantitative interpretation of immunoassays, given that strong immunoassay reactivity is a potential clue indicating possible HIT despite a (false) negative platelet activation assay. received

May 15, 2020

accepted after revision

July 20, 2020
DOI https://doi.org/

10.1055/a-1223-3329.

ISSN 0720-9355. (c) 2020 Georg Thieme Verlag KG Stuttgart · New York
License terms

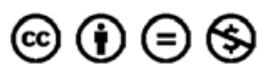


Zusammenfassung

\author{
Schlüsselwörter \\ - Chemilumineszenz- \\ Immunoassays \\ - Heparin-induzierte \\ Thrombozytopenie \\ - Latex- \\ Immunturbidimetrie- \\ Assay \\ - Serotoninrelease \\ Assay
}

Heparin-induzierte Thrombozytopenie (HIT) ist ein Antikörper-vermittelter Zustand der Hyperkoagulierbarkeit mit hohem Thromboserisiko und ausgeprägter Pathogenese unter Beteiligung von Immunglobulin G-vermittelter Thrombozytenaktivierung. Das Ziel der Immunantwort ist ein kationisches "Selbst" - Protein, Thrombozytenfaktor 4 (PF4), welches durch Heparin antigenisiert wird. Ein Schlüsselproblem ist, dass nur eine Minderheit der durch Heparin induzierten Anti-PF4/Polyanion-Antikörper pathogen und in der Lage ist, eine Blutplättchenaktivierung und damit eine klinische HIT zu verursachen. Da Thrombozytopenie häufig bei mit Heparin behandelten Patienten im Krankenhaus auftritt, sind Tests für "HIT-Antikörper" üblich; somit ist die Unterscheidung zwischen pathogenen und nicht pathogenen Antikörper wichtig. Das zentrale Konzept ist das diejenigen Antikörper, deren plättchenaktivierende Eigenschaften in vitro nachweisbar sind, gut mit Pathogenität korrelieren, wie durch Thrombozytenaktivierungstests wie den Serotoninrelease Assay (SRA) und Heparin-induzierten Thrombozytenaktivierungsassay gezeigt. In den meisten Fällen werden jedoch unter diesen Umständen Immunoassays als First-Line-Tests verwendet, daher ist es wichtig für Ärzte einzuschätzen, welche Immunoassay-Ergebnisprofile - im entsprechenden klinischen Kontext - das Vorhandensein von Blutplättchen-aktivierenden Antikörpern vorhersagen (Bayes'sche Analyse). Kliniker mit Zugang zu schnellen HIT-Immunoassays auf Abruf (z. B. Partikelgel Immunoassay, Latex-Immunturbidimetrie-Assay, Chemilumineszenz-Immunoassay) können über die einfache dichotome Ergebnisinterpretation hinausschauen („negativ“/,positiv“) und semiquantitative Interpretation einbeziehen, bei der zum Beispiel eine stark positives Immunoassay-Ergebnis (oder sogar die Kombination von zwei Immunoassays) auf eine größere Wahrscheinlichkeit des Nachweises plättchenaktivierender Antikörper hinweist und damit die Diagnose „HIT“ unterstützt. Die jüngste Anerkennung von „SRA-negativem HIT“ hat die Bedeutung der semiquantitativen Interpretation von Immunoassays erhöht, da eine starke Immunoassay Reaktivität ein Hinweis auf eine mögliche HIT trotz eines (falsch) negativen BlutplättchenAktivierungsassays sein kann.

\section{Introduction}

Heparin-induced thrombocytopenia (HIT) is a model "clinico-pathological" disorder with a clear nexus between "clinical" events (platelet count decline, laboratory markers of hypercoagulability, thrombotic events) and the key defining "pathological" feature, namely, detectability of heparin-dependent, platelet-activating antibodies reactive against platelet factor 4/heparin (PF4/H) complexes. ${ }^{1,2}$ Indeed, unlike other immunohematological disorders, where pathogenic platelet-reactive antibodies are detectable in only some patients (e.g., $\sim 50 \%$ of autoimmune thrombocytopenia, ${ }^{3} \sim 80 \%$ of neonatal alloimmune thrombocytopenia ${ }^{4}$ ), HIT antibodies can be detected in at least $99 \%$ of affected patients. ${ }^{5}$ Despite their high sensitivity, certain assays are not necessarily diagnostically specific, given the remarkable fact that heparin exposure often triggers an anti-PF4/H immune response that does not result in HIT. The challenge for the laboratory-and for the clinician tasked with interpreting laboratory test results-is to distinguish between pathogenic and nonpathogenic antibodies. Thus, HIT is a model disease for analyzing the correlates between in vitro antibody pathogenicity and a clinically evident disease. A further complication is that an otherwise pathologic antibody may not necessarily produce disease in a given patient, perhaps for patient-dependent factors. The purpose of this review is to discuss some determinants of antibody pathogenicity and how to identify them.

\section{History}

Despite longstanding heparin use, it took many years for the concept of HIT to become established and accepted by the medical community. One of the key contributing historical events was the demonstration of antibodies in patient blood. ${ }^{6,7}$

\section{HIT is Caused by Heparin-Dependent, Platelet- Activating Antibodies}

An early report laying the foundation of the HIT syndrome was authored in $1977^{7}$ by a medical student, Glen Rhodes, working with vascular surgeon Donald Silver and a hematology resident, Richard Dixon. They described eight patients who developed thrombocytopenia beginning approximately a week after starting either intravenous therapeutic-dose or subcutaneous prophylactic-dose heparin. All eight patients developed thrombotic events (although one stroke patient presented 
with hemorrhagic transformation). The authors demonstrated complement-fixing, heparin-dependent antibodies in five of their patients.

Other investigators subsequently demonstrated heparindependent platelet-activating antibodies using a variety of platelet activation endpoints, such as platelet aggregation and thromboxane release. ${ }^{8,9}$ Unfortunately, platelet aggregometry using platelet-rich plasma is unsatisfactory (sensitivity only $\sim 70 \%$, although with high specificity ${ }^{10}$ ).

In 1984, Sheridan and colleagues showed that "washing" platelets with resuspension in calcium/magnesium-containing buffer rendered them especially susceptible to heparindependent activation by serum from patients with HIT. ${ }^{11}$ Moreover, by selecting "pedigree" platelet donors (subjects whose platelets are readily activated by HIT sera) and by utilizing weak-positive HIT sera (for quality control), a sensitive and specific test for HIT became available. ${ }^{12}$ However, the platelet activation endpoint, namely the release of a radioactive label $\left({ }^{14} \mathrm{C}\right.$-serotonin), not to mention the technical challenges of platelet washing, meant that the assay was available in only a few reference laboratories, mainly in North America. In Europe, a modified washed platelet activation assay that utilized platelet aggregation (judged visually by the laboratory technologist), known as the heparin-induced platelet activation (HIPA) test, ${ }^{13}$ became adopted by some reference laboratories. ${ }^{14}$ Through wider availability of these assays, the laboratory underpinnings of HIT became established by 1990 .

\section{Platelet Activation Occurs through Platelet Fcylla Receptors}

In 1988, Kelton and coworkers demonstrated that HIT antibody-induced platelet activation occurs via cross-linking of platelet Fcylla receptors (low-affinity immunoglobulin G [IgG] receptors). ${ }^{15}$ The use of an Fc receptor-blocking monoclonal antibody further enhanced the diagnostic specificity of platelet activation assays, by proving that platelet activation has occurred through Fcylla receptors.

\section{The Target Antigen: PF4/Polyanion Complexes}

The identification of the target antigens of HIT remained elusive until 1992 when Amiral and coworkers demonstrated that a cationic protein within platelet $\alpha$-granules, PF4, formed HIT antigen(s) by binding to heparin. ${ }^{16}$ This discovery led to the availability of a commercial PF4/H enzyme immunoassay (EIA) for detecting these antibodies. However, it quickly became apparent that the frequency of anti-PF4/H antibodies detected among heparin-exposed patients greatly exceeded the relatively small proportion of heparin-exposed patients who developed clinically evident HIT. ${ }^{17,18}$ Thus, a research challenge was to identify the factors that resulted in antibody pathogenicity.

\section{Timeline of Antibody Detectability}

Studies of serial blood samples obtained from clinical trials of patients exposed to heparin have shown a remarkable property, namely the detection of antibodies by EIA at the earliest onset of the HIT-related platelet count fall. - Fig. 1 shows the typical timeline of the HIT immune response. ${ }^{19}$ The IgGspecific EIA first becomes positive 4 days (median) following initiation of heparin, with the onset of the platelet count fall occurring 2 days later (median, day 6 ), with development of a $50 \%$ or greater fall in the platelet count 2 days later (median, day 8); thrombotic events occur at a median of day 10 , although the temporal range of thrombosis occurrence is wide. Another unusual aspect of the anti-PF4/H immune response is that antibodies of any of the three major immunoglobulin classes-IgG, $\operatorname{IgA}$, and $\operatorname{IgM}$-can be formed, either singly or in any combination; however, only IgG antibodies are clearly associated with clinical HIT. Moreover, the timeline of antibody generation is the same among the three classes, i.e., there is no IgM precedence ${ }^{19,20}$; thus, the HIT immune response differs from the classic primary immune response.

\section{Implications for Pathogenesis}

The ready detection of free antibodies within patient serum or plasma shortly before the onset of the platelet count fall indicating HIT, whether assessed by PF4-dependent immunoassay ${ }^{19,21}$ or by SRA, ${ }^{22}$ is a remarkable feature of HIT. We believe these observations have important implications for HIT pathogenesis: we have proposed ${ }^{5,21}$ that the high sensitivity of serum/plasma-based assays for HIT antibodies indicates that high levels of free (unbound) HIT antibodies are required to produce the dynamic conditions essential to form the multimolecular PF4-polyanion complexes on platelet surfaces needed to engage and cross-link platelet Fcrlla receptors, leading to platelet activation.

This concept ties in with the dynamic model of platelet activation proposed by Newman and Chong, ${ }^{23}$ whereby antiPF4/H IgG (from plasma) binds via its Fab moieties to PF4/H complexes formed on the surface of activated platelets; only subsequently does the Fc portion of the bound $\operatorname{IgG}$ engage with Fc receptors on the same or adjacent platelets. In this dynamic model of platelet activation, PF4 released from platelets progressively enhances further antibody binding and additional platelet release, in a positive-feedback manner.

\section{Iceberg Model of HIT}

The classic iceberg model, shown in - Fig. 2, shows clinical HIT as being caused by a subset of anti-PF4/H antibodies that cause in vitro platelet activation. ${ }^{24}$ In this model, platelet activation assays, such as the SRA and HIPA, have similar high sensitivity to PF4-dependent EIAs, for diagnosis of HIT; however, platelet activation assays have far greater diagnostic specificity, as they do not detect nonpathogenic, nonplatelet-activating antibodies. Moreover, -Fig. 2 also includes the concept of greater degree of reactivity of the EIA as a prediction of the greater likelihood of the presence of (platelet-activating) HIT antibodies.

\section{Platelet-Activating Properties}

By far the most important feature that predicts the pathogenicity of HIT antibodies is the presence of platelet-activating 

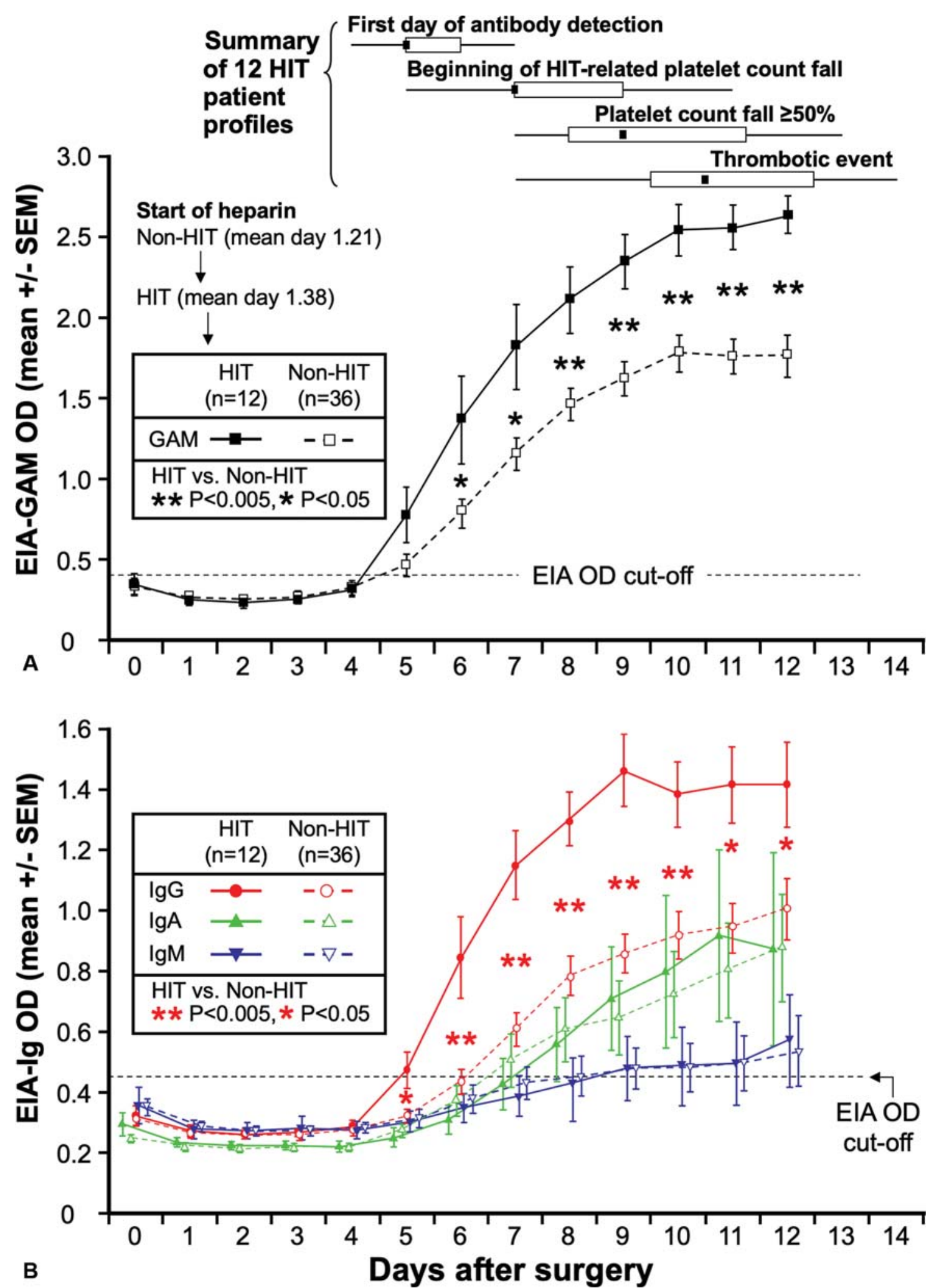

Fig. 1 Timeline of the HIT immune response. (A) The temporal relationship between antibody detection, onset and progression of platelet count fall, and HIT-associated thrombosis. Patients with HIT $(n=12)$ had higher values in a commercial polyspecific EIA (GAM) compared with antibody-positive patients who did not develop HIT $(n=36)$, even though the non-HIT patients were selected for optical density (OD) values of at least 1.00 unit. (B) Anti-PF4/heparin antibodies and HIT: comparison of IgG, IgA, and IgM classes. Higher levels of IgG anti-PF4/heparin antibodies -as judged by OD values-were observed in the patients with HIT versus the antibody-positive non-HIT patients. In contrast, IgA and IgM levels were similar between HIT and non-HIT patients. The same 48 subjects were studied for both parts of the figure. All 12 HIT patients exhibited at least a $50 \%$ decline in the platelet count. (Adapted from Warkentin et al $2009^{19}$.) EIA, enzyme-immunoassay; HIT, heparin-induced thrombocytopenia; IgG, immunoglobulin G; PF4, platelet factor 4. 


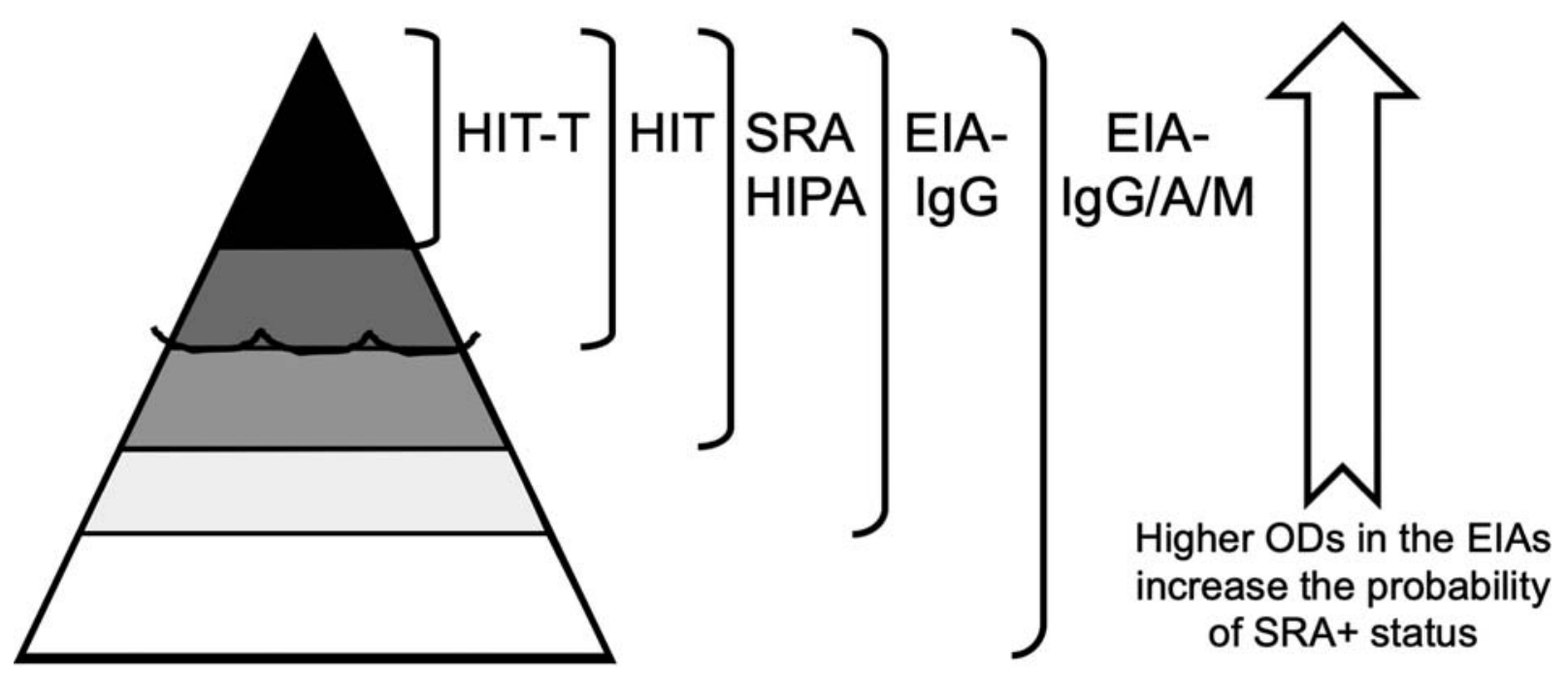

\begin{tabular}{|l|c|c|c|c|c|c|}
\hline EIA-IgG/AM result (OD units) & $<0.40$ & $\mathbf{0 . 4 0 - 0 . 9 9}$ & $1.00-1.49$ & $1.50-1.99$ & $2.00-2.99$ & $>3.00$ \\
\hline Probability of SRA+ status: & $<1 \%$ & $\sim 5 \%$ & $\sim 25 \%$ & $\sim 50 \%$ & $\sim 90 \%$ & $\sim 99 \%$ \\
\hline
\end{tabular}

Fig. 2 Iceberg model as interpreted by the SRA (or HIPA) and EIAs (polyspecific vs. IgG-specific). Also shown is the approximate probability of a positive SRA for different strengths of reactivity in the EIA. The figure makes the assumption that the SRA and HIPA provide similar information (although this might not necessarily be true). ElA-lgG, IgG-specific enzyme-immunoassay; ElA-lgG/A/M, polyspecific ElA that detects antibodies of IgG, IgA, and/or lgM classes; HIT, (isolated) heparin-induced thrombocytopenia; HIT-T, HIT-associated thrombosis; ODs, optical densities; SRA, serotonin-release assay (Hematology Am Soc Hematol Educ Program. 2011; 2011: 143-149; doi: 10.1182/asheducation-2011.1.143). [rerif].

Table 1 Various definitions of HIT: impact on frequency of HIT

\begin{tabular}{|c|c|c|c|c|c|}
\hline \multirow[t]{2}{*}{ Definition of HIT } & \multicolumn{2}{|c|}{$\begin{array}{l}\text { Number of cases } \\
\text { meeting definition }\end{array}$} & \multicolumn{2}{|c|}{$\begin{array}{l}\text { Number with } \\
\text { thrombosis }\end{array}$} & \multirow[t]{2}{*}{ Reference } \\
\hline & $\begin{array}{l}\text { UFH } \\
(n=332)\end{array}$ & $\begin{array}{l}\text { LMWH } \\
(n=333)\end{array}$ & $\begin{array}{l}\text { UFH } \\
(n=332)\end{array}$ & $\begin{array}{l}\text { LMWH } \\
(n=333)\end{array}$ & \\
\hline SRA + ; platelet count fall $>50 \%$; nadir $<150 \times 10^{9} / \mathrm{L}$ & 9 & 0 & 8 & 0 & 26 \\
\hline SRA +; platelet count fall >50\%; nadir $>150 \times 10^{9} / \mathrm{L}$ & $7^{\mathrm{a}}$ & $2^{b}$ & 4 & 1 & 27 \\
\hline SRA + ; platelet count fall 30-49.9\%; nadir $>150 \times 10^{9} / \mathrm{L}$ & 0 & $1^{\mathrm{b}}$ & 0 & 1 & 22 \\
\hline SRA + ; platelet count fall $<30 \%$ but abnormal profile ${ }^{c}$ & 5 & 0 & 0 & 0 & 22 \\
\hline PF4-SRA + ; platelet count fall >50\% & $1^{d}$ & 0 & 1 & 0 & 21 \\
\hline Total (i.e., meeting any of the above definitions) & $22(6.6 \%)$ & $3(0.9 \%)$ & $13(3.9 \%)$ & $2(0.6 \%)$ & \\
\hline
\end{tabular}

Abbreviations: LMWH, low-molecular-weight heparin; PF4-SRA + , PF4-enhanced serotonin-release assay-positive; SRA + , serotonin-release assaypositive; UFH, unfractionated heparin.

${ }^{a}$ Four of these seven patients had probable HIT based on: $>50 \%$ platelet count fall (nadir $>150 \times 10^{9} / \mathrm{L}$ ) that began 5 or more days after starting heparin, without alternative explanation; however, blood was not available to test for HIT antibodies (these four patients are presumed to be SRApositive for the purposes of this table).

${ }^{\mathrm{b}}$ Three SRA-positive patients in the LMWH study arm only met the definition of thrombocytopenia $(>50 \%, n=2 ; 30-49.9 \%, n=1)$ after receiving therapeutic-dose UFH for suspected thrombosis (thrombosis was confirmed in two of the patients).

${ }^{\mathrm{C}}$ Abnormal profile indicates platelet fall to less than a (antibody-negative) 25-patient cohort that had similar initial platelet counts as the SRA + patient.

'This patient was diagnosed as having "SRA-negative HIT."

antibodies. Insight into this fundamental aspect of HIT was provided by analysis of blood samples collected during a thromboprophylaxis trial that compared unfractionated heparin (UFH) with the low-molecular-weight heparin (LMWH), enoxaparin. The original trial, performed on 665 patients (UFH, $n=332$; LMWH, $n=333$ ), was reported in $1991 .^{25}$ My research project was to evaluate the occurrence and frequency of HIT in this trial. The resulting initial publication $^{26}$ identified nine patients who developed HIT, based on (1) platelet count fall to less than $150 \times 10^{9} / \mathrm{L}$, that (2) began 5 or more days after starting heparin, and (3) with a positive SRA. Subsequent studies ${ }^{21,22,27}$ reporting on this database and blood sample repository led to development of more expansive concepts of the definition of HIT.

- Table 1 shows the numbers of patients with putative HIT in the 665-patient trial, based on various definitions of thrombocytopenia, including use of an absolute threshold (e.g., a platelet count fall to below $150 \times 10^{9} / \mathrm{L}$ ), and a 
proportional threshold (e.g., $>50 \%$ platelet count fall irrespective of any absolute threshold). Another analysis examined whether a patient's platelet counts fell below a particular cohort band, based on the preoperative platelet count value shared between the patient and an otherwise similar (but non-antibody-forming) patient cohort. - Table 1 also includes the single patient in the trial subsequently identified as having "SRA-negative HIT,"21 a concept discussed later.

A striking feature of the data shown in -Table 1 is the markedly higher frequency of HIT associated with UFH versus $\mathrm{LMWH}$, the main conclusion of our initial report. ${ }^{26}$ The greater frequency of HIT with UFH (vs. LMWH) has been confirmed by other studies, including via meta-analysis. ${ }^{28}$

Presence of platelet-activating antibodies, as shown by a positive SRA within a study subgroup systematically tested for HIT antibodies, strongly predicted for thrombocytopenia: 12/21 (57.1\%) SRA-positive patients developed thrombocytopenia ( $>50 \%$ platelet count fall) versus only $3 / 341(0.9 \%)$ who tested SRA-negative (odds ratio, $\sim 150$ ). Of the three SRAnegative patients who developed thrombocytopenia, two had the same non-HIT explanation for thrombocytopenia (bowel perforation with septicemia), and the third patient was the aforementioned patient believed to have SRA-negative HIT (discussed subsequently in the section "SRA-Negative HIT").

HIT Breakthrough: Role of Type and Dose of Heparin Another interesting finding from the trial was that the difference in risk of HIT between UFH and LMWH appears to reflect two distinct factors, "immunogenicity" and "breakthrough." UFH (vs. LMWH) resulted in a higher antibody frequency, indicating a greater immunogenicity of UFH. However, three patients in the LMWH arm of the study did not develop thrombocytopenia until after they had been switched to therapeutic-dose UFH because of suspicion for thrombosis. This suggests that UFH may be more likely than LMWH to result in "breakthrough" of HIT in an SRA-positive patient, particularly when given in therapeutic doses. Further evidence for dual roles in immunization and breakthrough was found in our analysis of a later trial of UFH versus LMWH (dalteparin) in critical illness ${ }^{29}$; in this study, several SRA-positive patients developed further platelet count declines (and, in one instance, a fatal acute anaphylactoid reaction), after switching from prophylactic-dose LMWH or UFH to therapeutic-dose UFH. Additional support for this concept was seen in the trials of fondaparinux thromboprophylaxis and treatment; whereas anti-PF4/H antibody frequency (immunogenicity) was similar between LMWH and fondaparinux, ${ }^{30,31}$ breakthrough of HIT occurred when UFH or LMWH-but not fondaparinux-was given to SRA-positive patients. ${ }^{31,32}$ The implication of these studies is that clinical factors other than antibody pathogenicity per se -such as the type and dose of heparin received-must be important in influencing HIT occurrence.

The biological basis for these differences in immunogenicity and breakthrough was explored by Greinacher and colleagues. ${ }^{33}$ Using atomic force microscopy, they reported that HIT antigens are formed through close approximation of (positively charged) PF4 tetramers that occurs via charge neutralization through binding to any of the three polyanions, UFH, LMWH, and fondaparinux. However, the complexes formed between PF4 and the polyanions differed considerably, with the greatest number and sizes of PF4: polyanion complexes occurring in the rank order UFH $>$ LMWH $>>$ fondaparinux.

\section{IgG versus Non-IgG Anti-PF4/H Antibodies}

-Fig. 3 summarizes the PF4-dependent antibody profiles of a patient subgroup evaluated as part of the clinical trial summarized in -Table 1. Within this patient subgroup, we identified 25 patients who had detectable plateletactivating antibodies ( 24 by SRA; 1 additional patient identified by a modified SRA discussed later in this review). All SRA-positive patients had detectable IgG class antibodies, consistent with the key role of IgG in causing HIT through platelet activation via Fcylla receptors. These data explain why IgG-specific EIAs are more specific (without significant loss of sensitivity) for a diagnosis of HIT versus polyspecific EIAs that also detect antibodies of IgM and IgA classes, as shown by numerous studies $^{34-36}$ as well as by a systematic review. ${ }^{37}$ These observations support a recommendation of the International Society on Thrombosis and Haemostasis in favor of IgG-specific EIAs over polyspecific EIAs. ${ }^{2}$ A practical implication of these observations is that IgA and IgM anti-PF4/H antibodies-although commonly detected in heparin-exposed patients-appear unlikely to cause HIT, at least in the absence of IgG antibodies (a dual role of IgA and/or IgM antibodies in facilitating platelet activation by IgG antibodies remains possible).

There are several important messages depicted by - Fig. 3 :

- The frequency of antibody formation is greater with UFH versus LMWH (larger size of geometric shapes).

- The frequency of forming antibodies of the three major immunoglobulin classes-IgG, IgA, and IgM (indicated by the relative sizes of the corresponding colored circles)-is similar.

- Some patients form antibodies of two or even all three of the major immunoglobulin classes.

- Platelet-activating antibodies (i.e., SRA-positive status, as shown by the dashed rectangles) are found only among patients with IgG class antibodies.

- Patients who developed HIT ( $>50 \%$ platelet count fall) are a subset of patients who have platelet-activating-and hence IgG class-antibodies, without a clear additional association with IgA and/or IgM antibodies.

- There is an overall greater frequency of clinically evident HIT with UFH versus LMWH.

\section{Strength of EIA Reactivity}

A third feature of pathogenicity is the strength of EIA reactivity, as judged by optical density (OD) readings. This is illustrated in - Fig. 1B, which shows higher OD values in the EIA-IgG among patients who developed HIT versus (control) EIA-IgG-positive patients who did not develop 


\section{PF4-reactive Abs (UFH): 79/189 (41.8\%)}

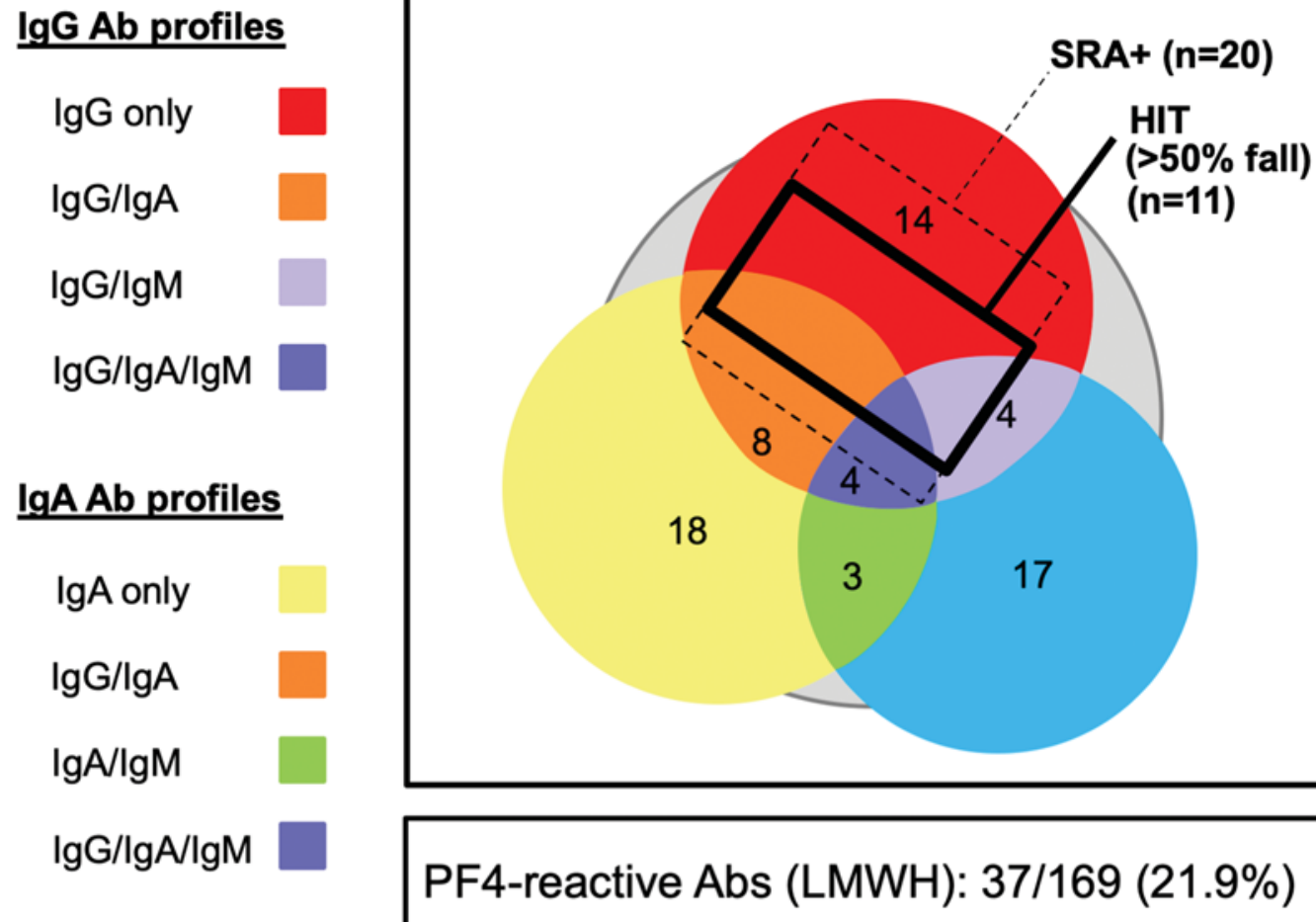

IgM Ab profiles

IgM only

$\lg G / \lg M$

$\lg \mathrm{A} / \lg \mathrm{M}$

$\lg \mathrm{G} / \lg \mathrm{A} / \lg \mathrm{M}$

\section{Polyspecific IgG/A/M Abs}

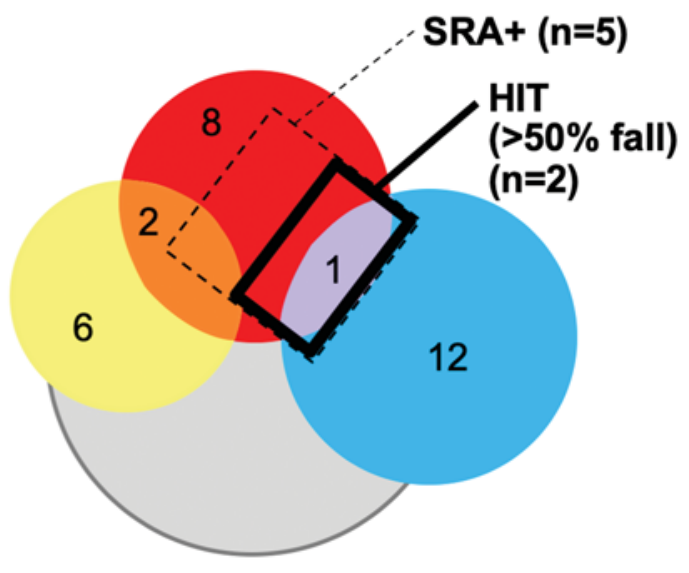

Fig. 3 PF4-reactive antibodies in a clinical trial of UFH versus LMWH. The area occupied by the geometric shapes within each large square is proportional to the overall frequency of PF4-reactive antibodies (Abs) detected. The data are from a 358-patient subgroup (UFH, $n=189$; LMWH, enoxaparin, $n=169$ ) from a clinical trial ${ }^{25-27}$ for which data were available for four PF4-dependent EIAs (three class-specific in-house PF4/H-EIAs-lgG, IgA, and IgM-and one polyspecific PF4/polyvinylsulfonate (PVS) EIA from Immucor GTI Diagnostics (Waukesha, Wisconsin, United States). Thus, 41.8\% (79/189) of the area within the top square occupied by the geometric shapes indicates the proportion of patients who received UFH and had detectable PF4-reactive antibodies, and 21.9\% (37/169) of the area within the bottom square occupied by the geometric shapes indicates the proportion of patients who received LMWH and had detectable PF4-reactive antibodies. The areas of the various colored geometric shapes indicate the relative numbers of patients who tested positive for the various combinations of antibody classes, with the absolute numbers for each group indicated within each distinct colored shape. The exposed gray area represents the patients who tested positive in the polyspecific PF4/PVS-EIA but negative in all three of the class-Specific PF4/H-EIAs. The area of the rectangles with solid black lines indicates the numbers of patients with $\mathrm{HIT}$, as defined by $>50 \%$ platelet count fall in association with a positive test for platelet-activating antibodies, classic SRA-positive (SRA + ; UFH, $n=10$; LMWH, $n=2$ ) and PF4-SRA-positive (PF4-SRA + ; UFH, $n=1$ ) for total of 13 HIT patients meeting this definition of HIT. The area of the larger dashed rectangles indicates the numbers of patients with a positive SRA (classic SRA, $n=24$; PF4-SRA, $n=1$, for total of 25 patients with plateletactivating antibodies). EIA, enzyme-immunoassay; HIT, heparin-induced thrombocytopenia; LMWH, low-molecular-weight heparin; PF4, platelet factor 4; SRA, serotonin-release assay; UFH, unfractionated heparin. 
HIT. Studies have shown that the strength of EIA reactivity $^{38,39}$ and of certain rapid immunoassays (quantitated via a sample titer yielding a positive result ${ }^{40}$ ) predicts for a higher frequency of a positive platelet activation assay and/or a diagnosis of clinically evident HIT. Higher ODs reflect greater antibody quantities and binding avidity. The iceberg model (-Fig. 2) summarizes the frequency of SRApositive status (surrogate for clinical HIT) at various OD ranges of EIA reactivity: the probability of positive SRA status ranged from $<1 \%$ (EIA negative) to $\sim 5 \%$ (weak OD reactivity) all the way to $\sim 90 \%$ for OD values that are 2.00 or higher.

\section{Location of Target Antigen(s) within PF4}

The precise location of the antigen(s) within the PF4 molecule recognized by anti-PF4/H antibodies plays a role in antibody pathogenicity. More than one target antigen within PF4 are recognized by PF4/H antibodies, with certain epitopes being more pathogenic. ${ }^{41,42}$

A HIT-like monoclonal antibody, KKO, was developed by Arepally and coworkers. ${ }^{43} \mathrm{KKO}$ has been incorporated into an automated immunoassay based on competitive inhibition for binding to PF4/polyanion between HIT antibodies and KKO. The high sensitivity ( 95\%) of this assay for HIT $^{44}$ (discussed in the section "Rapid Immunoassays for HIT") suggests that most HIT antigens are located at or near the target region recognized by KKO.

\section{SRA-Positive Status without HIT}

Analysis of the clinical trial subset summarized in -Fig. 3 reveals that some SRA-positive subjects did not develop HIT (using definition of $>50 \%$ platelet count fall). Some patients developed more subtle platelet count abnormalities (such as those identified based on a platelet count decrease below the antibody-negative cohort band derived from similar preoperative platelet count values). Nevertheless, some SRA-negative patients did not evince an abnormal platelet count profile. In some instances, the patients were discharged to home relatively early (e.g., postoperative day 8), even though most received a study drug (UFH vs. enoxaparin) for a full 2 weeks; it is possible these SRA-positive patients would have developed a platelet count fall indicating HIT if they had continued to receive heparin for several more days (HIT antibodies usually peak between day 10 and 14 following initial receipt of the immunizing heparin exposure $\left.\mathrm{e}^{20,21}\right)$. The phenomenon of SRA-positive status without clinically overt HIT has not been well studiedgiven the paucity of such patients identified-but potential explanations could include (1) "weaker" platelet-activating antibodies (i.e., SRA-positive status ranges from those sera yielding only $20 \%$ serotonin release to others that consistently trigger $100 \%$ serotonin release) reflecting differences in HIT antibody titer, affinity, IgG subclass, or specific antigen target site; (2) suboptimal platelet responsiveness to HIT antibody stimulation due to patient-specific platelet factors (e.g., low Fc receptor numbers, Fc receptor genotype, low levels of platelet-associated PF4, etc.), and (3) use of antiplatelet medications.

\section{Rapid Immunoassays for HIT}

Although EIAs can be performed within several hours, for practical reasons, they are usually performed in batches, no more than once daily in laboratories that offer this assay. However, in recent years, there has been a major focus on developing on-demand immunoassays aimed at helping to provide rapid diagnosis. Some of these immunoassays yield a dichotomous endpoint (positive, negative), whereas others yield a numerical output (allowing for varying strength of reactivity). This section will focus on three rapid immunoassays, the particle gel immunoassay (PaGIA), the chemiluminescent immunoassay (CLIA), and the latex immunoturbidimetric assay (LIA). For these three assays, there is substantial experience integrating test results within the appropriate clinical context, particularly from the viewpoint of altering a pretest probability into a posttest probability (Bayesian reasoning), including graded predictivity based on strength of reactivity. More recently, studies have been reported in which two rapid immunoassays are used in combination.

\section{Particle Gel Immunoassay}

The PaGIA (ID-H/PF4-PaGIA; DiaMed, Cressier sur Morat, Switzerland) is the oldest rapid HIT immunoassay. ${ }^{45}$ The test uses red, high-density polystyrene particles to which $\mathrm{PF} 4 / \mathrm{H}$ complexes are bound; after addition of patient serum or plasma, anti-PF4/H antibodies bind to the antigen-coated beads. However, as IgG antibodies do not agglutinate polystyrene beads well, a secondary antihuman immunoglobulin antibody is added into the sephacryl gel. The principle of gel centrifugation assays is that-upon centrifugation-the agglutinated beads (indicating presence of anti-PF4/H antibodies) do not migrate through the sephacryl gel (strong positive result), whereas nonagglutinated beads (indicating absence of antibodies) pass through the gel, thus forming a red band at the bottom (negative result). A weak positive result is indicated by dispersal of the particles throughout the gel. The assay is technically easy, can be performed rapidly, with results read visually. The method is available to blood banks that utilize a manual gel centrifugation technology system. The PaGIA is not cleared by the U.S. Food and Drug Administration.

Assessment of PaGIA reactivity using diluted test-positive sera can be helpful for quality control ${ }^{46}$; moreover, sample titer of reactivity can be helpful for estimating a positive predictive value (PPV). ${ }^{40}$ Although the manufacturer of the PaGIA recommends against sample dilution, this situation has parallels with the use of OD values in interpreting EIA results: the U.S. Food and Drug Administration has only approved PF4dependent EIAs as "qualitative" (positive/negative) assays, but most laboratories routinely report OD values, given the enormous differences in PPV between weak-positive and strong-positive EIA results.

\section{IgG Chemiluminescent Immunoassay}

The CLIA (HemosIL AcuStar HIT-IgG $(\mathrm{PF} 4-\mathrm{H})$, Instrumentation Laboratory, Bedford, Massachusetts, United States) detects anti-PF4/H antibodies based on their ability to bind to magnetic particles coated with PF4/polyanion complexes on their 
surfaces, with a labeled anti-IgG antibody resulting in a luminescent reaction. The assay is performed on demand using an automated instrument. In our laboratory, ${ }^{47}$ this assay had $98 \%$ sensitivity and $98 \%$ specificity when using stored samples that had been evaluated in a prospective study evaluating the 4Ts pretest scoring probability. Although the manufacturer's cutoff of $1.0 \mathrm{U} / \mathrm{mL}$ implies a qualitative "positive" versus "negative" interpretation, the readout is semiquantitative, with greater likelihood of HIT with greater reactivity.

\section{Latex Immunoturbidimetric Immunoassay}

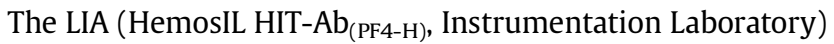
can be viewed as a "functionalized immunoassay," 48 as it detects HIT antibodies based on their ability to inhibit agglutination of latex beads to which the HIT-mimicking monoclonal antibody (KKO) has been bound, in the presence of PF4/ polyanions. In our laboratory, ${ }^{44}$ this assay had approximately 95\% sensitivity and 95\% specificity when using stored samples that had been evaluated in a prospective study that evaluated the 4Ts pretest scoring system. Although the manufacturer's cutoff of $1.0 \mathrm{U} / \mathrm{mL}$ implies a qualitative "positive" versus "negative" interpretation, like the CLIA, the readout is semiquantitative. As discussed subsequently, considering the magnitude of reactivity provides additional useful diagnostic information.

\section{Integrating Pretest Probability and Rapid Immunoassay Results}

Several groups have investigated the integration of pretest probability-as judged by a clinical scoring system such as the $4 \mathrm{Ts}^{49,50}$-together with the rapid immunoassay, the PaGIA. ${ }^{51-53}$ Some studies focused on the issue of ruling out HIT, i.e., defining the clinical and laboratory parameters that make a diagnosis of HIT most unlikely. ${ }^{51,53}$ In one study, ${ }^{53}$ patients judged to be at low probability of HIT were treated differently from non-low risk patients (prophylactic- vs. therapeutic-dose alternative anticoagulation pending receipt of the gold standard SRA). Another group of investigators found that incorporation of certain semiquantitative informationsuch as a high-titer positive PaGIA (titer $1 / 32$ or higher)pointed to a $100 \%$ PPV for diagnosis of HIT. ${ }^{52}$

Our group has performed modeling studies to determine how other rapid immunoassays ${ }^{44,47}$ could be integrated into a Bayesian model of HIT diagnosis, particularly incorporating the value of semiquantitative data. For example, when analyzing results of the LIA, for a patient judged to have an intermediate pretest probability of HIT of approximately 8 to $10 \%$, the ranges of posttest probabilities for a patient testing negative $(<1.0 \mathrm{U} / \mathrm{mL})$, weak-positive (1.0-4.9 U/mL), intermediate-positive (5.0-15.9 U/mL), or strong-positive ( $\geq 16 \mathrm{U} / \mathrm{mL}$ ) were determined to be, respectively, $<1, \sim 35-40, \sim 70-75$, and $\sim 90-95 \%$. For the CLIA, the respective probabilities (using the same $U / \mathrm{mL}$ cutoffs) were determined to be $<1,55-60,90-95$, and $>99 \%$. Clearly, the strength of reactivity of these rapid immunoassays is highly predictive with respect to determining antibody pathogenicity.

\section{Integrating Pretest Probability and Two Rapid Immunoassays}

Recently, two groups ${ }^{54,55}$ have reported results integrating clinical and laboratory parameters, in which two rapid assays were combined. Part of the rationale of dual testing is to reduce risk of false-negative tests, given the treatment implications of missing a diagnosis of HIT.

Marchetti and coworkers ${ }^{54}$ performed real-time evaluation of two rapid immunoassays, one a first-line assay (CLIA) and the other a second-line assay (PaGIA); samples were tested later, as required, by EIA and HIPA. A novel concept was the use of extreme positive- and negative-result thresholds, e.g., a CLIA $>3 \mathrm{U} / \mathrm{mL}$ suggesting approximately $100 \%$ PPV and a CLIA $<0.13 \mathrm{U} / \mathrm{mL}$ indicating $0 \%$ negative predictive value (NPV); corresponding extreme PPV and NPV values for the PaGIA titer of $\geq 16$ and $\leq 1$ were also used. Their major finding was that for approximately $95 \%$ of referrals to the laboratory, an accurate positive diagnosis of HIT ( $~ 7 \%$ of patients) or correct exclusion of HIT ( $\sim 88 \%$ of patients) could be achieved within 60 minutes after sample receipt.

Recently, our group reported on modeling studies integrating the results of the CLIA and LIA in influencing assessment of posttest probability. We developed a 6-point laboratory scoring system wherein results were classified as negative $(<1.0 \mathrm{U} / \mathrm{mL}$; 0 points), weak-positive (1.0-4.9 U/mL; 1 point), intermediatepositive (5.0-15.9 $\mathrm{U} / \mathrm{mL} ; 2$ points), and strong-positive $(\geq 16.0$ $\mathrm{U} / \mathrm{mL}$; 3 points); thus, 6 points could be achieved if both the LIA and CLIA yielded strong-positive results. By combining the LIA and CLIA assays, test sensitivity exceeded 99\% (i.e., similar to the false-negative risk of a single PF4-dependent EIA). We also found a striking increase in probability of a positive SRA that ranged from a low of approximately 5\% (1 point, i.e., weakpositive in the LIA or CLIA and negative in the other) to a high of at least $97 \%$ (for samples testing strong-positive in both assays). - Fig. 4 shows the probability of SRA-positive status for samples referred to our laboratory (irrespective of pretest probability) for varying strengths of reactivity for the LIA and for the CLIA, interpreted separately. In addition, we show the probability of SRA-positive status when the LIA and CLIA results are interpreted together, using the aforementioned 6-point scale. Interestingly, the results are not unlike those seen with semiquantitative interpretation of the EIAs: for example, a score of 1 point in combined LIA/CLIA testing predicts a $5 \%$ probability of HIT (per SRA-positive status), not unlike a weak-positive EIA (0.40-0.99 OD units), just like a score of 3 points predicts for an approximately $60 \%$ probability of SRA-positive status, similar to an EIA yielding an OD of approximately 1.50 to 1.99 OD units (-Fig. 1 ). - Fig. 4 also shows the likelihood of the sample containing platelet-activating antibodies (as detected by either the classic SRA or by use of an SRA modified to enhance detection of platelet-activating antibodies); for samples scoring 4 points or higher in the 6point scale, the probability of detecting platelet-activating antibodies was approximately $98 \%$.

-Fig. 4 also depicts an updated iceberg model of HIT from the perspective of the rapid immunoassays, the LIA and the CLIA. An important concept is that a strong reactivity in the LIA and CLIA points to a high probability of HIT even when 


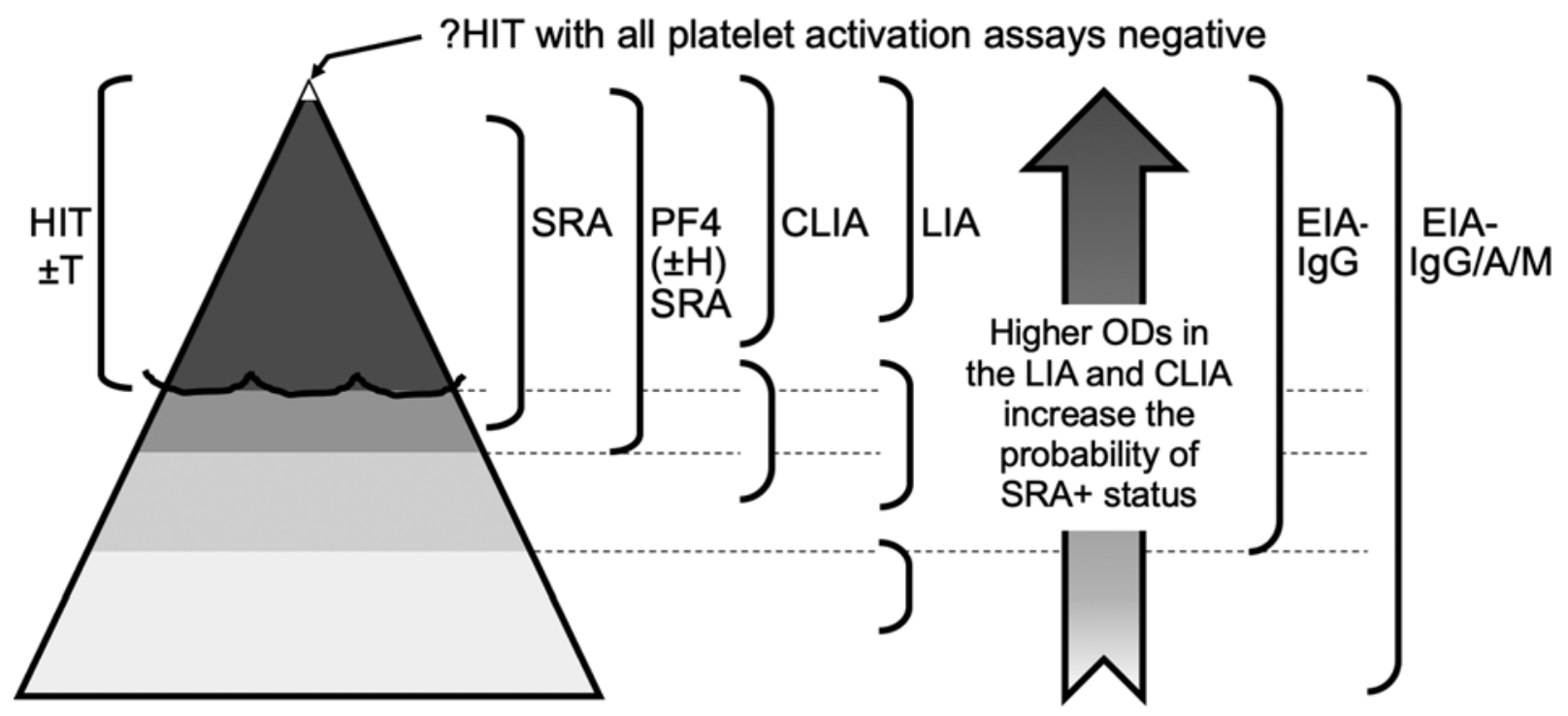

\begin{tabular}{|l|c|c|c|c|}
\hline LIA or CLIA-IgG result (U/mL) & $<1.00$ & $1.00-4.99$ & $5.00-15.99$ & $\geq 16.00$ \\
\hline Probability of HIT (SRA+ status) per LIA result & $<1 \%$ & $\sim 30 \%$ & $\sim 70 \%$ & $\sim 90 \%$ \\
\hline Probability of HIT (SRA+ status) per CLIA result & $<1 \%$ & $\sim 50 \%$ & $\sim 90 \%$ & $>95 \%$ \\
\hline
\end{tabular}

\begin{tabular}{|l|c|c|c|c|c|c|c|}
\hline Dual LIA and CLIA analysis (6 point scale) & $\mathbf{0}$ & $\mathbf{1}$ & $\mathbf{2}$ & $\mathbf{3}$ & $\mathbf{4}$ & $\mathbf{5}$ & $\mathbf{6}$ \\
\hline Probability of HIT (SRA+ status) & $<1 \%$ & $\sim 5 \%$ & $\sim 30 \%$ & $\sim 60 \%$ & $\sim 80 \%$ & $\sim 95 \%$ & $>97 \%$ \\
\hline Probability of platelet-activating Abs & $<3 \%$ & $\sim 10 \%$ & $\sim 55 \%$ & $\sim 85 \%$ & & $\sim 98 \%$ \\
\hline
\end{tabular}

Fig. 4 Iceberg model updated per current concepts. The part of the iceberg that protrudes above the waterline indicates patients with HIT $\pm T$ (HIT with or without thrombosis). The large iceberg represents the totality of antibodies detected by polyspecific PF4-dependent EIA (EIA-IgG/A/ $M)$, with a large subgroup comprising patients with detectable PF4-reactive antibodies of IgG class (EIA-IgG). The vast majority of HIT cases are detected by serotonin-release assay (SRA), with most SRA-negative HIT detectable by a modified SRA, either the PF4-SRA or the PF4/H-SRA (collectively indicated as "PF4( $\pm \mathrm{H}$ )-SRA"). The LIA and CLIA both have relatively high sensitivity for HIT, with the CLIA (an IgG-specific immunoassay) correlating more closely with EIA-IgG than the LIA (which can also detect IgA and IgM class antibodies). Although the model implies $100 \%$ sensitivity of the EIA-IgG and EIA-IgG/A/M, in reality, an occasional HIT case will be negative in one commercial EIA but test positive in another. The model also indicates that there may be occasional patients with HIT who test strongly positive by EIA, LIA, and/or CLIA, but in whom platelet-activating antibodies are difficult to detect. The model also indicates that the probability of HIT increases with increasing reactivity by LIA and/or CLIA (including interpreting both tests together). CLIA, chemiluminescent immunoassay; EIA, enzyme-immunoassay; HIT, heparin-induced thrombocytopenia; LIA, latex immunoturbidimetric assay.

the patient tests negative in the (conventional) SRA. This observation provides a segue to the emerging topic of "SRAnegative HIT."

\section{SRA-Negative HIT}

We have historically regarded the McMaster SRA to have a high sensitivity for HIT, at least $95 \%{ }^{24}$ However, the SRA is technically challenging, and could have lower sensitivity in laboratories that perform the assay differently, or that do not utilize pedigree donors. Nonetheless, there could also be certain HIT sera that are not readily detectable by SRA. In 2016, Padmanabhan and colleagues ${ }^{56}$ described patients with a clinical picture consistent with HIT, strong EIA reactivity, but consistent SRA-negative reactivity. These authors showed that by performing a modified platelet activation assay in which PF4 is added, rather than heparin, these patients' sera could produce platelet activation, as measured by P-selectin expression (assessed by flow cytometry). These investigators, from Versiti (formerly, the BloodCenter of Wisconsin), suggested that the sensitivity of their SRA might be as low as $50 \%{ }^{56}$

Our laboratory has independently shown that the sensitivity of our SRA could also be enhanced by measuring patient serum-dependent serotonin release in the presence of high concentrations of PF $4(50-100 \mu \mathrm{g} / \mathrm{mL})$, rather than heparin, in a modified assay we called the "PF4-SRA."21,57,58 In our first report describing the PF4-SRA, ${ }^{57}$ we found that the additional patients identified as having platelet-activating antibodies did not appear to have a clinical picture suggestive of HIT. In other words, it seemed plausible that (conventional) SRA-negative blood samples that tested positive in the PF4-SRA might be similar to SRA-negative/EIA-positive blood samples, in that the patients most likely did not have HIT.

However, more recent studies ${ }^{21,58}$ from our group do support the concept of SRA-negative HIT. In one study, we systematically evaluated 27 EIA-positive/SRA-negative samples by PF4-SRA; we found one patient with plausible SRAnegative HIT on both clinical and laboratory grounds. As 
these 27 samples had been obtained from a prospective study that identified 35 patients with (SRA-positive) HIT, this indicated the McMaster SRA to have a sensitivity of approximately $97 \%$ (35/36).

In the other study, we evaluated seroconversion by LIA in stored plasmas from the clinical trial for which results are summarized in -Table 1 . To our surprise, we found that one patient we had previously considered as being HIT-negative (based on SRA-negative status), but who exhibited both LIA and EIA seroconversion, tested positive in the PF4-SRA. The clinical picture indeed was compatible with HIT ( $>50 \%$ platelet count fall that began on day 7 of heparin treatment complicated by pulmonary embolism). This single patient with SRA-negative HIT, identified among at least 20 other SRA-positive patients ( - Table 1 )-depending on the definition of HIT-also indicates a sensitivity of the McMaster SRA of at least $95 \%$.

This raises important questions: should the PF4-SRA (or other PF4-enhanced platelet activation assays) represent a new gold standard for diagnosing HIT? This is unclear-as we do not know whether PF4-enhanced assays (like using the EIA alone) will increase frequency of false-positive diagnosis. Or, should the PF4-SRA be held in reserve, and only be performed in those patients in whom the clinician has a strong suspicion for HIT, despite a negative SRA. Another unknown is whether the HIPA test could reliably identify some of the HIT sera that test negative by SRA (or perhaps even using a PF4-enhanced SRA). This possibility is raised by observations that some SRA-negative sera can test HIPA-positive, although certain technical considerations (e.g., assays performed in different laboratories using different platelet donors) and absence of clinical data have limited conclusions regarding the significance of these findings. 59,60

\section{Platelet-Activating Antibody-Negative HIT}

The central dogma of HIT for the past 35 years has been the central role of heparin-dependent, platelet-activating antibodies detectable in patient serum or plasma. This raises an important question: is it possible to diagnose HIT when all platelet activation assays, including the HIPA, SRA, PF4-SRA, PF4/H-SRA, or other PF4-enhanced assays, are negative?

Marchetti and coworkers ${ }^{54}$ identified 10 patients in a population of 687 patients evaluated for HIT whose clinical picture and combination of rapid assays suggested a likely diagnosis of HIT, despite the negative (gold standard) HIPA test. In general, these patients were EIA- and PaGIA-positive, and most also tested positive in the CLIA (and even the CLIA"negative" patients had values $>0.40 \mathrm{U} / \mathrm{mL}$, a threshold that may have $100 \%$ sensitivity for HIT antibodies ${ }^{47}$ ). In some instances, a plausible explanation for a false-negative HIPA was identified (e.g., the patient was receiving ticagrelor, with the platelet inhibition carryover affecting the in vitro platelet activation test ${ }^{61}$ ).

In our recent report evaluating use of two rapid immunoassays for diagnosis of HIT, ${ }^{55}$ we identified a patient who tested strongly positive by CLIA and moderately positive by LIA, and whose serum also tested strongly positive by EIA-IgG. However, three platelet activation assays-the SRA, PF4-SRA, and PF4/ H-SRA-were all negative. When we evaluated the case clinically, our judgment was that the patient might well have had HIT. ${ }^{55}$ This raises the troubling issue of whether HIT can occur when platelet activation assays are repeatedly negative. We believe this HIT patient category-if it truly exists-must be uncommon. However, it remains problematic regarding how to define and detect this disorder.

\section{Final Comments}

HIT represents an intriguing clinico-pathological disorder in which the high frequency of anti-PF4/heparin antibodies triggered by heparin exposure, and the key pathogenic role of a subset of antibodies with potent platelet-activating properties, is a model disease for studying features of antibody pathogenicity. Although the long-standing paradigm of antibody pathogenicity correlating strongly with positive testing in (washed) platelet activation assays has endured through three decades, the occasional "exception that proves the rule" means that there is still more to unravel. Strength of reactivity in semiquantitative rapid immunoassays, especially when combined with clinical probability scores, will increasingly influence real-time management decisions with the potential to improve evaluation and treatment of patients with clinically suspected HIT.

\section{Conflicts of Interest}

Prof. Theodore E. Warkentin declares the following conflicts of interest: consulting fees from Bayer, CSL Behring, Ergomed, and Octapharma; research support and consulting fees from Instrumentation Laboratory; royalties from Informa (Taylor and Francis); and consulting fees related to medical-legal expert testimony regarding HIT and nonHIT thrombocytopenic and coagulopathic disorders.

\section{References}

1 Warkentin TE, Chong BH, Greinacher A. Heparin-induced thrombocytopenia: towards consensus. Thromb Haemost 1998;79 (01):1-7

2 Warkentin TE, Greinacher A, Gruel Y, Aster RH, Chong BHScientific and Standardization Committee of the International Society on Thrombosis and Haemostasis. Laboratory testing for heparininduced thrombocytopenia: a conceptual framework and implications for diagnosis. J Thromb Haemost 2011;9(12): 2498-2500

3 Vrbensky JR, Moore JE, Arnold DM, Smith JW, Kelton JG, Nazy I. The sensitivity and specificity of platelet autoantibody testing in immune thrombocytopenia: a systematic review and meta-analysis of a diagnostic test. J Thromb Haemost 2019;17(05):787-794

4 Mueller-Eckhardt C, Kiefel V, Grubert A et al. 348 cases of suspected neonatal alloimmune thrombocytopenia. Lancet 1989;1(8634):363-366

5 Warkentin TE. Laboratory diagnosis of heparin-induced thrombocytopenia. Int J Lab Hematol 2019;41(Suppl 1):15-25

6 Rhodes GR, Dixon RH, Silver D. Heparin induced thrombocytopenia with thrombotic and hemorrhagic manifestations. Surg Gynecol Obstet 1973;136(03):409-416 
7 Rhodes GR, Dixon RH, Silver D. Heparin induced thrombocytopenia: eight cases with thrombotic-hemorrhagic complications. Ann Surg 1977;186(06):752-758

8 Chong BH, Pitney WR, Castaldi PA. Heparin-induced thrombocytopenia: association of thrombotic complications with heparindependent $\operatorname{IgG}$ antibody that induces thromboxane synthesis in platelet aggregation. Lancet 1982;2(8310):1246-1249

9 Stricker H, Lämmle B, Furlan M, Sulzer I. Heparin-dependent in vitro aggregation of normal platelets by plasma of a patient with heparin-induced skin necrosis: specific diagnostic test for a rare side effect. Am J Med 1988;85(05):721-724

10 Brodard J, Alberio L, Angelillo-Scherrer A, Nagler M. Accuracy of heparin-induced platelet aggregation test for the diagnosis of heparin-induced thrombocytopenia. Thromb Res 2020;185:27-30

11 Sheridan D, Carter C, Kelton JG. A diagnostic test for heparininduced thrombocytopenia. Blood 1986;67(01):27-30

12 Warkentin TE, Hayward CPM, Smith CA, Kelly PM, Kelton JG. Determinants of donor platelet variability when testing for heparininduced thrombocytopenia. J Lab Clin Med 1992;120(03):371-379

13 Greinacher A, Michels I, Kiefel V, Mueller-Eckhardt C. A rapid and sensitive test for diagnosing heparin-associated thrombocytopenia. Thromb Haemost 1991;66(06):734-736

14 Eichler P, Budde U, Haas S et al. First workshop for detection of heparin-induced antibodies: validation of the heparin-induced platelet-activation test (HIPA) in comparison with a PF4/heparin ELISA. Thromb Haemost 1999;81(04):625-629

15 Kelton JG, Sheridan D, Santos A et al. Heparin-induced thrombocytopenia: laboratory studies. Blood 1988;72(03):925-930

16 Amiral J, Bridey F, Dreyfus M et al. Platelet factor 4 complexed to heparin is the target for antibodies generated in heparin-induced thrombocytopenia. Thromb Haemost 1992;68(01):95-96

17 Amiral J, Bridey F, Wolf M et al. Antibodies to macromolecular platelet factor 4-heparin complexes in heparin-induced thrombocytopenia: a study of 44 cases. Thromb Haemost 1995;73(01):21-28

18 Warkentin TE, Sheppard JA, Horsewood P, Simpson PJ, Moore JC, Kelton JG. Impact of the patient population on the risk for heparininduced thrombocytopenia. Blood 2000;96(05):1703-1708

19 Warkentin TE, Sheppard JA, Moore JC, Cook RJ, Kelton JG. Studies of the immune response in heparin-induced thrombocytopenia. Blood 2009;113(20):4963-4969

20 Greinacher A, Kohlmann T, Strobel U, Sheppard JA, Warkentin TE. The temporal profile of the anti-PF4/heparin immune response. Blood 2009;113(20):4970-4976

21 Warkentin TE, Sheppard JI, Smith JW, Arnold DM, Nazy I. Timeline of heparin-induced thrombocytopenia seroconversion in serial plasma samples tested using an automated latex immunoturbidimetric assay. Int J Lab Hematol 2019;41(04):493-502

22 Warkentin TE, Arnold DM, Kelton JG, Sheppard JI, Smith JW, Nazy I. Platelet-activating antibodies are detectable at the earliest onset of heparin-induced thrombocytopenia, with implications for the operating characteristics of the serotonin-release assay. Chest 2018;153(06):1396-1404

23 Newman PM, Chong BH. Heparin-induced thrombocytopenia: new evidence for the dynamic binding of purified anti-PF4heparin antibodies to platelets and the resultant platelet activation. Blood 2000;96(01):182-187

24 Warkentin TE. How I diagnose and manage HIT. Hematology (Am Soc Hematol Educ Program) 2011;2011:143-149

25 Levine MN, Hirsh J, Gent M et al. Prevention of deep vein thrombosis after elective hip surgery. A randomized trial comparing low molecular weight heparin with standard unfractionated heparin. Ann Intern Med 1991;114(07):545-551

26 Warkentin TE, Levine MN, Hirsh J et al. Heparin-induced thrombocytopenia in patients treated with low-molecular-weight heparin or unfractionated heparin. N Engl J Med 1995;332(20):1330-1335

27 Warkentin TE, Roberts RS, Hirsh J, Kelton JG. An improved definition of immune heparin-induced thrombocytopenia in postoperative orthopedic patients. Arch Intern Med 2003;163(20):2518-2524
28 Martel N, Lee J, Wells PS. Risk for heparin-induced thrombocytopenia with unfractionated and low-molecular-weight heparin thromboprophylaxis: a meta-analysis. Blood 2005;106(08):2710-2715

29 Warkentin TE, Sheppard JI, Heels-Ansdell D, et al; Canadian Critical Care Trials Group and the Australian and New Zealand Intensive Care Society Clinical Trials Group. Heparin-induced thrombocytopenia in medical surgical critical illness. Chest 2013;144(03):848-858

30 Warkentin TE, Cook RJ, Marder VJ et al. Anti-platelet factor 4/ heparin antibodies in orthopedic surgery patients receiving antithrombotic prophylaxis with fondaparinux or enoxaparin. Blood 2005;106(12):3791-3796

31 Warkentin TE, Cook RJ, Marder VJ, Greinacher A. Anti-PF4/heparin antibody formation postorthopedic surgery thromboprophylaxis: the role of non-drug risk factors and evidence for a stoichiometry-based model of immunization. J Thromb Haemost 2010;8(03):504-512

32 Warkentin TE, Davidson BL, Büller HR et al. Prevalence and risk of preexisting heparin-induced thrombocytopenia antibodies in patients with acute VTE. Chest 2011;140(02):366-373

33 Greinacher A, Gopinadhan M, Günther JU et al. Close approximation of two platelet factor 4 tetramers by charge neutralization forms the antigens recognized by HIT antibodies. Arterioscler Thromb Vasc Biol 2006;26(10):2386-2393

34 Lindhoff-Last E, Gerdsen F, Ackermann H, Bauersachs R. Determination of heparin-platelet factor 4-IgG antibodies improves diagnosis of heparin-induced thrombocytopenia. Br J Haematol 2001; 113(04):886-890

35 Warkentin TE, Sheppard JA, Moore JC, Moore KM, Sigouin CS, Kelton JG. Laboratory testing for the antibodies that cause heparin-induced thrombocytopenia: how much class do we need? J Lab Clin Med 2005;146(06):341-346

36 Pouplard C, Leroux D, Regina S, Rollin J, Gruel Y. Effectiveness of a new immunoassay for the diagnosis of heparin-induced thrombocytopenia and improved specificity when detecting IgG antibodies. Thromb Haemost 2010;103(01):145-150

37 Husseinzadeh HD, Gimotty PA, Pishko AM, Buckley M, Warkentin TE, Cuker A. Diagnostic accuracy of IgG-specific versus polyspecific enzyme-linked immunoassays in heparin-induced thrombocytopenia: a systematic review and meta-analysis. J Thromb Haemost 2017;15(06):1203-1212

38 Warkentin TE, Sheppard JI, Moore JC, Sigouin CS, Kelton JG. Quantitative interpretation of optical density measurements using PF4-dependent enzyme-immunoassays. J Thromb Haemost 2008;6(08):1304-1312

39 Zwicker JI, Uhl L, Huang WY, Shaz BH, Bauer KA. Thrombosis and ELISA optical density values in hospitalized patients with heparin-induced thrombocytopenia. J Thromb Haemost 2004;2(12): 2133-2137

40 Alberio L, Kimmerle S, Baumann A, Taleghani BM, Biasiutti FD, Lämmle B. Rapid determination of anti-heparin/platelet factor 4 antibody titers in the diagnosis of heparin-induced thrombocytopenia. Am J Med 2003;114(07):528-536

41 Suh JS, Aster RH, Visentin GP. Antibodies from patients with heparininduced thrombocytopenia/thrombosis recognize different epitopes on heparin: platelet factor 4. Blood 1998;91(03):916-922

42 Li ZQ Liu W, Park KS et al. Defining a second epitope for heparininduced thrombocytopenia/thrombosis antibodies using KKO, a murine HIT-like monoclonal antibody. Blood 2002;99(04):1230-1236

43 Arepally GM, Kamei S, Park KS et al. Characterization of a murine monoclonal antibody that mimics heparin-induced thrombocytopenia antibodies. Blood 2000;95(05):1533-1540

44 Warkentin TE, Sheppard JI, Linkins LA, Arnold DM, Nazy I. Performance characteristics of an automated latex immunoturbidimetric assay [HemosIL ${ }^{\circledR}$ HIT-Ab $_{(\mathrm{PF} 4-\mathrm{H})}$ ] for the diagnosis of immune heparin-induced thrombocytopenia. Thromb Res 2017;153:108-117

45 Meyer O, Salama A, Pittet N, Schwind P. Rapid detection of heparin-induced platelet antibodies with particle gel immunoassay (ID-HPF4). Lancet 1999;354(9189):1525-1526 
46 Schneiter S, Colucci G, Sulzer I, Barizzi G, Lämmle B, Alberio L. Variability of anti-PF4/heparin antibody results obtained by the rapid testing system ID-H/PF4-PaGIA. J Thromb Haemost 2009;7 (10):1649-1655

47 Warkentin TE, Sheppard JI, Linkins LA, Arnold DM, Nazy I. High sensitivity and specificity of an automated IgG-specific chemiluminescence immunoassay for diagnosis of HIT. Blood 2018;132 (12):1345-1349

48 Warkentin TE. Demand on-demand testing for the diagnosis of heparin-induced thrombocytopenia. Thromb Res 2016; 140:163-164

49 Warkentin TE, Heddle NM. Laboratory diagnosis of immune heparin-induced thrombocytopenia. Curr Hematol Rep 2003;2 (02):148-157

50 Lo GK, Juhl D, Warkentin TE, Sigouin CS, Eichler P, Greinacher A. Evaluation of pretest clinical score (4 T's) for the diagnosis of heparin-induced thrombocytopenia in two clinical settings. J Thromb Haemost 2006;4(04):759-765

51 Pouplard C, Gueret P, Fouassier M et al. Prospective evaluation of the '4Ts' score and particle gel immunoassay specific to heparin/PF4 for the diagnosis of heparin-induced thrombocytopenia. J Thromb Haemost 2007;5(07):1373-1379

52 Nellen V, Sulzer I, Barizzi G, Lämmle B, Alberio L. Rapid exclusion or confirmation of heparin-induced thrombocytopenia: a single-center experience with 1,291 patients. Haematologica 2012;97(01):89-97

53 Linkins LA, Bates SM, Lee AYY, Heddle NM, Wang G, Warkentin TE. Combination of 4Ts score and PF4/H-PaGIA for diagnosis and management of heparin-induced thrombocytopenia: prospective cohort study. Blood 2015;126(05):597-603
54 Marchetti M, Barelli S, Zermatten MG et al. Rapid and accurate Bayesian diagnosis of heparin-induced thrombocytopenia. Blood 2020;135(14):1171-1184

55 Warkentin TE, Sheppard JI, Smith JW et al. Combination of two complementary automated rapid assays for diagnosis of heparininduced thrombocytopenia (HIT). J Thromb Haemost 2020;18 (06):1435-1446

56 Padmanabhan A, Jones CG, Curtis BR et al. A novel PF4-dependent platelet activation assay identifies patients likely to have heparininduced thrombocytopenia/thrombosis. Chest 2016;150(03): 506-515

57 Nazi I, Arnold DM, Warkentin TE, Smith JW, Staibano P, Kelton JG. Distinguishing between anti-platelet factor $4 /$ heparin antibodies that can and cannot cause heparin-induced thrombocytopenia. J Thromb Haemost 2015;13(10):1900-1907

58 Warkentin TE, Nazy I, Sheppard JI, Smith JW, Kelton JG, Arnold DM. Serotonin-release assay-negative heparin-induced thrombocytopenia. Am J Hematol 2020;95(01):38-47

59 Savi P, Chong BH, Greinacher A et al. Effect of fondaparinux on platelet activation in the presence of heparin-dependent antibodies: a blinded comparative multicenter study with unfractionated heparin. Blood 2005;105(01):139-144

60 Eekels JJM, Althaus K, Bakchoul $\mathrm{T}$ et al. An international external quality assessment for laboratory diagnosis of heparininduced thrombocytopenia. J Thromb Haemost 2019;17(03): 525-531

61 Eekels JJM, Pachler C, Krause N, Muhr T, Waltl G, Greinacher A. Ticagrelor causes false-negative functional tests for heparininduced thrombocytopenia. Blood 2020;135(11):875-878 